\title{
CARACTERIZAÇÃO DA VIA DAS LIPOXIGENASES EM PLANTAS DE SOJA RESISTENTES E SUSCEPTÍVEIS A DIAPHORTE PHASEOLORUM F.SP. MERIDIONALIS, AGENTE CAUSAL DO CANCRO-DA-HASTE
}

\author{
MARCELO DIAS DA SILVA ${ }^{1}$, MARIA GORETI DE ALMEIDA OLIVEIRA ${ }^{2}$, ANNA \\ CRISTINA LANNA ${ }^{3}$, CHRISTIANO VIEIRA PIRES ${ }^{4}$, NEWTON DENIZ PIOVESAN ${ }^{5}$, \\ INÊS CHAMEL JOSÉ ${ }^{6}$, ROSA BÁRBARA ${ }^{1}$ BATISTA, EVERALDO GONÇALVES DE \\ BARROS $^{7}$ E MAURILIO ALVES MOREIRA ${ }^{8}$.
}

Universidade Federal de Viçosa - 36.570-000 - Viçosa - MG

\begin{abstract}
RESUMO - Lipoxigenases (linoleato: oxigênio oxido-redutase - EC 1.13.11.12) são dioxigenases que catalisam a adição do oxigênio molecular ao sistema cis, cis, 1,4 - pentadieno dos ácidos graxos polinsaturados, formando hidroperóxidos dos ácidos graxos correspondentes. As lipoxigenases vegetais utilizam o ácido linolênico (C18:3) ou ácido linoléico (C18:2) como substrato e estão associadas a importantes processos fisiológicos, tais como: biossíntese de compostos regulatórios, crescimento e desenvolvimento, senescência, germinação de sementes, resposta a ferimento, proteína de reserva vegetativa e resistência a insetos e patógenos. Quando os tecidos da planta são danificados por patógenos ou mecanicamente, ocorre uma degradação seqüencial de lipídeos, cujo produto inicial são os hidroperóxidos resultante da ação das lipoxigenases. Entre os vários produtos formados, têm-se a traumatina, o ácido jasmônico, os aldeídos voláteis e os oxiácidos. Para avaliar a capacidade de as plantas de soja responderem, por meio da Via das Lipoxigenases, ao ataque do fungo causador da doença cancroda-haste - Diaphorte phaseolorum (Cke. e Ell) $f$. sp. meridionalis - foram realizadas a caracterização bioquímico-cinética do pool de lipoxigenases foliares de plantas de soja (Glycine max (L.) Merril ) e a quantificação dos produtos da Via das Lipoxigenases, utilizando-se um cultivar resistente (FT-Cristalina $\mathrm{RCH}$ ) e um susceptível (FT-Cristalina) ao patógeno. As plantas dos dois cultivares, infectadas com o patógeno ou apenas injuriadas mecanicamente, apresentaram valores de atividade específica de lipoxigenases maiores que os respectivos controles, em diferentes valores de $\mathrm{pH}$ e temperatura, e o pool de lipoxigenases dos dois genótipos apresentou cinética de Michaelis-Menten na faixa de concentração de substrato analisada. Ocorreu aumento dos níveis de inibidores de proteases e aldeídos totais, os quais são produtos dessa via bioquímica. Pelos parâmetros bioquímico e cinético, há a sugestão de uma resposta das plantas de soja através das Via das Lipoxigenases .
\end{abstract}

TERMOS ADICIONAIS PARA INDEXAÇÃO: Glycine max, lipoxigenase, Diaporthe phaseolorum, aldeídos, inibidores de protease.

Recebido: 18/6/2001 - Aceito: 16/10/2001

1. MS em Agroquímica pela Universidade Federal de Viçosa.

2. Professora Adjunto do Departamento de Bioquímica e Biologia Molecular/ BIOAGRO, UFV - CEP:36570 - 000, Viçosa, MG e-mail:malmeida@mail.ufv.br.

3. Doutoranda em Fisiologia Vegetal, UFV.

4. Mestrando em Agroquímica, UFV.

5. Técnico de Nível Superior, BIOAGRO/UFV.

6. Doutoranda em Tecnologia de Alimentos, UFV.

7. Professor Titular do Departamento de Biologia Geral/ BIOAGRO, UFV.

8. Professor Titular do Departamento de Bioquímica e Biologia Molecular/ BIOAGRO, UFV. 


\title{
CHARACTERIZATION OF LIPOXYGENASE PATHWAY OF SOYBEAN PLANTS RESISTANT AND SUSCEPTIBLE TO DIAPHORTE PHASEOLORUM F.SP. MERIDIONALIS, PATHOGEN RESPONSIBLE FOR STEM CANKER
}

\begin{abstract}
Lipoxygenases (linoleate: oxygen oxido-reductases, EC 1.13.11.12) are a class of enzymes that catalyze the addition of molecular oxygen to 1,4 - cis,cis - pentadiene motifs of unsaturated fatty acids to form hydroperoxide products. Plant lipoxygenases use linoleic (18:2) or linolenic (18:3) acids as substrates and are involved in important physiological process such as biosynthesis of regulatory molecules, growth and development, senescence, responses to wounding, vegetative storage protein and may directly mediate host resistance to insect, fungal and bacterial pathogens. When plant tissues are damaged, by pathogens or mecanically injured, a series of lipid degradation occurs, via lipoxygenase pathway, giving rise to hydroperoxydes. Among several products formed it can be found traumatin, jasmonic acid, volatile aldehydes and oxyacids. In this work we evaluated the capacity of the soybean plant to respond to the attack of stem canker fungi (Diaporthe phaseolorum (Cke. e Ell.) f. sp. meridionalis), through the lipoxygenase pathway. Leaves from resistant (FT-Cristalina $\mathrm{RCH}$ ) and susceptible (FT-Cristalina) cultivars were used for kinetic evaluation of lipoxygenase and biochemical quantitation of products from the lipoxygenase pathway. Plants from both cultivars, infected with the pathogen or mecanically injured, showed values of lipoxygenase specific activity higher than the controls in differents $\mathrm{pH}$ and temperature values. The lipoxygenase pool of both cultivars showed kinetic of Michaelis-Menten within the range of substrate concentration assayed. There were an increase in protease inhibitors and of total aldehydes contents, which are products of the lipoxygenase pathway. The biochemical and kinetic parameters suggest a response of the soybean plant through the lipoxygenase pathway.
\end{abstract}

ADDITIONAL INDEX TERMS: Glycine max, lipoxygenase, Diaporthe phaseolorum, aldehydes, protease inhibitors.

\section{INTRODUÇÃO}

As lipoxigenases (LOX) são isoenzimas que estão amplamente distribuídas em plantas e animais superiores. Elas catalisam a adição do oxigênio molecular ao sistema pentadieno dos ácidos graxos polinsaturados, formando hidroperóxidos dos ácidos graxos correspondentes e contêm ferro não-heme, que é necessário para sua atividade catalítica (Axelrod et al., 1981; Mack et al., 1987; Vick e Zimmerman, 1987; Bunker et al., 1995).

As lipoxigenases vegetais utilizam ácido linolênico (C18:3) ou ácido linoléico (C18:2) como substrato e estão envolvidas na biossíntese de compostos regulatórios, tais como o ácido traumático e ácido jasmônico (Anderson et al., 1989; Farmer e Ryan, 1992; Bunker et al., 1995), o crescimento e desenvolvimento (Hildebrand, 1989; Siedow, 1991), senescência (Rouet-Mayer et al., 1992), germinação de sementes (Park et al., 1994), resposta a ferimento (Vieira et al., 2001), reserva vegetativa (Tranbarger et al., 1991; Bunker et al., 1995; Stephenson et al., 1998) e resistência a insetos e patógenos (Bell e Mullet, 1993; Melan et al., 1993; Croft et al., 1993; Saravitz e Siedow, 1996; Heitz et al., 1997; Bohland et al., 1997; Fidantsef e Bostock, 1998; Silva, 1999).

Durante um processo de estresse, ocorrem danos físicos às células e, em razão disso, uma degradação seqüencial de lipídeos pode ser iniciada pelas lipoxigenases. Essas formam hidroperóxidos de ácidos graxos, que são rapidamente metabolizados para formar vários produtos. Dentre esses, estão a traumatina, 
envolvida na resposta a ferimentos e na indução da divisão celular e formação de calos (Siedow, 1991), o ácido jasmônico, associado à ativação de genes que codificam para a síntese de proteínas de reserva e inibidores de proteases (Melan et al., 1993), os aldeídos voláteis e oxiácidos, que causam efeito inibitório sobre o crescimento de fungos patogênicos (Vaughn e Gardner, 1993), insetos e protozoários (Croft et al., 1993). Esses aldeídos possivelmente agem também como um sinal químico na atração do inimigo natural do herbívoro para a planta danificada (Paré e Tumlinson, 1997).

Entre as doenças que atacam a cultura da soja, cita-se o cancro-da- haste, causado pelo fungo Diaphorte phaseolorum (Cke. e Ell) $f$. $s p$. meridionalis, que acomete as plantas provocando necrose nas folhas e avermelhamento nas hastes. Essa enfermidade causa a morte da planta entre a floração e o enchimento das vagens, podendo levar a perdas de 80 a $100 \%$. A doença está presente em todas as áreas produtoras de soja do País e o seu controle exige integração de todas as medidas capazes de reduzir o potencial de inóculo do patógeno na lavoura, como: uso de cultivares resistentes, tratamento de semente, rotação/sucessão de culturas, manejo do solo com a incorporação dos restos culturais, escalonamento de épocas de semeadura e adubação equilibrada (EMBRAPA, 2000).

Com este trabalho objetivou-se realizar uma avaliação bioquímica e cinético-enzimática da Via das Lipoxigenases, em plantas de soja resistente (FT-Cristalina RCH) e susceptível (FTCristalina) ao fungo Diaphorte phaseolorum f. sp. meridionalis, agente causador do cancro-da-haste, a fim de verificar se a planta de soja produz uma resposta ao patógeno através dessa via bioquímica.

\section{MATERIAIS E MÉTODOS}

\section{Material genético}

Foram utilizadas plantas de soja (Glycine $\max$ (L.) Merril) do cultivar comercial FTCristalina e uma linhagem derivada desse cultivar
FT-Cristalina RCH, resistente ao cancro-da-haste. Sementes de FT-Cristalina foram fornecidas pelo banco de germoplasma de soja do Departamento de Fitotecnia da UFV, ao passo que o cultivar FTCristalina $\mathrm{RCH}$ foi desenvolvido pelo Programa de Melhoramento de Soja, BIOAGRO/UFV, pelo método de retrocruzamento, tendo como progenitor doador da resistência o cultivar DOKO RC. As plantas foram cultivadas em casa-de-vegetação, em vasos com capacidade para 4,0 $\mathrm{kg}$ de solo, num total de 336 vasos contendo 3 plantas cada um.

\section{Fonte de enzimas}

Foram utilizadas folhas de soja dos cultivares FT-Cristalina e FT-Cristalina RCH, no estádio V3 de desenvolvimento (Fehr et al.,1971). Os três folíolos da segunda folha trifoliolar, completamente expandidas, foram coletados, congelados em nitrogênio líquido e armazenados $\mathrm{a}-80^{\circ} \mathrm{C}$.

\section{Origem e preparo do inócuo}

Foi utilizado o $\mathrm{CH}$ 08, isolado de $D$. phaseolorum, nas inoculações. Esse foi fornecido pelo Centro Nacional de Pesquisa da Soja (EMBRAPA - Soja) e obtido de hastes de soja do cultivar Davis, proveniente do município de Palmeiras, Paraná. O isolado foi multiplicado e cedido pelo Programa de Melhoramento de Soja do Departamento de Fitotecnia de UFV.

\section{Inoculação das plantas}

Foi realizada a inoculação com palito de dente de madeira colonizado com o micélio fúngico, de acordo com a técnica descrita por Yorinori (1995). As inoculações foram feitas introduzindo-se o palito colonizado na haste principal das plantas, acima $1,5 \mathrm{~cm}$ das folhas unifolioladas, no estádio V3 de desenvolvimento (Fehr et al., 1971). Para constatar se a resposta seria de fato provocada pelo fungo, foram preparados dois grupos de plantas-controle: um grupo que foi inoculado apenas com o palito não colonizado pelo fungo e o outro grupo que não 
recebeu nenhum tipo de tratamento. Imediatamente após inoculação e 24, 48 e 96 horas após esses tratamentos, os três folíolos da segunda folha trifoliolar, completamente expandida, foram coletados, congelados em nitrogênio líquido e armazenados $\mathrm{a}-80^{\circ} \mathrm{C}$ para posterior obtenção dos extratos foliares.

\section{Obtenção dos extratos foliares}

A fonte de uma proteína é, em geral, um tecido animal, vegetal ou, então, células microbianas. As células precisam ser rompidas e a proteína obtida em uma solução chamada de extrato bruto (Lehninger et al., 1995). Assim, o preparo do extrato bruto foi realizado a $4^{\circ} \mathrm{C}$, de acordo com o método de Ohta et al. (1986), com as seguintes modificações: tampão fosfato de sódio $0,05 \mathrm{M} \mathrm{pH} 6,5$, em substituição ao tampão fosfato $0,1 \mathrm{M} \mathrm{pH} 6,5$, além de não ter sido utilizado Triton $\mathrm{X}-100$.

Os folíolos pesados e imediatamente congelados em nitrogênio líqüido foram triturados em almofariz. O pó obtido foi macerado em tampão fosfato de sódio $0,05 \mathrm{M}, \mathrm{pH}$ 6,5, na proporção $1: 3(\mathrm{p} / \mathrm{v})$ e, em seguida, centrifugado a $17200 \mathrm{x} g$ por 30 minutos a $4^{\circ} \mathrm{C}$. O sobrenadante, denominado extrato bruto, foi submetido à determinação de proteínas pelo método do ácido bicinconínico (Smith et al., 1985) e à determinação da atividade de lipoxigenases pelo método espectrofotométrico, utilizando-se linoleato de sódio como substrato (Axelrod et al., 1981). Todas as análises foram realizadas com cinco repetições.

\section{Determinação da atividade de lipoxigenases}

A atividade de lipoxigenases sobre o ácido linoléico foi determinada segundo o método descrito por Axelrod et al. (1981). Nesse método, é determinado o aumento da absorvância a $234 \mathrm{~nm}$, resultante da formação de um sistema de duplas ligações conjugadas no hidroperóxido formado.

Preparou-se uma solução-estoque de linoleato de sódio $10 \mathrm{mM}$, utilizando-se ácido linoléico, aproximadamente 99\% (SIGMA), como se segue: a um erlenmeyer envolvido por papel alumínio, contendo aproximadamente $10 \mathrm{~mL}$ de água deionizada, previamente fervida, foram adicionados $78 \mu \mathrm{L}$ de ácido linoléico e $90 \mu \mathrm{L}$ de Tween 20 (SIGMA). Em seguida, homogeneizouse a solução, succionando com auxílio de uma pipeta automática e tomando-se o cuidado para não formar bolhas. Para o clareamento da solução, foram adicionadas gotas de solução de hidróxido de sódio $0,5 \mathrm{~N}$. Após o clareamento, a solução foi transferida para um balão volumétrico de $25 \mathrm{~mL}$ envolvido por papel-alumínio e o volume aferido. A solução-estoque de linoleato de sódio foi armazenada em tubos eppendorf de $1 \mathrm{~mL}$, envolvidos em papel alumínio e armazenados a $20^{\circ} \mathrm{C}$.

Para as análises das atividades de lipoxigenases, misturaram-se $1,0 \mu \mathrm{L}$ do extrato bruto foliar e 4,0 $\mu \mathrm{L}$ da solução-estoque de linoleato de sódio em $1,0 \mathrm{~mL}$ de tampão fosfato $50,0 \mathrm{mM}, \mathrm{pH}$ 6,0. A velocidade da reação foi determinada de 30 em 30 segundos, a $234 \mathrm{~nm}$, por um período de 120 segundos. Sob as mesmas condições, procedeu-se com o branco, que consistiu da mesma quantidade de substrato e tampão. Experiência anterior do Laboratório de Enzimologia, BIOAGRO/UFV, demonstrou que nessas condições de reação a atividade é linear com o tempo. Todas as incubações foram realizadas com cinco repetições.

Por meio de regressão linear dos valores de absorvância a $234 \mathrm{~nm}$ obtidos a cada 30 segundos, até 120 segundos, foram calculadas as velocidades de formação dos produtos, expressas em V $\left(M . s^{-1}\right)$, utilizando-se a seguinte equação:

$$
\mathrm{V}=\frac{\mathrm{A} 234}{\varepsilon .1 . \mathrm{t}}
$$

em que:

$\mathrm{A}_{234}=$ absorvância a $234 \mathrm{~nm}$

$\varepsilon=25000 \mathrm{M}^{-1} \cdot \mathrm{cm}^{-1}$ (coeficiente de extinção molar dos hidroperóxidos do ácido linoléico a $234 \mathrm{~nm}$ ).

$\mathrm{t}=120$ segundos (tempo de análise).

$1=1,0 \mathrm{~cm}$ (caminho ótico). 
Atividade específica é o número de unidades de enzima por miligrama de proteína (Lehninger et al., 1995). Assim, os valores de atividade específica foram obtidos dividindo-se os valores de atividade pela concentração de proteínas e foram expressos em V(M.s $\left.{ }^{-1} / \mathrm{mg}\right)$.

Determinação da atividade de lipoxigenases em vários valores de $\mathrm{pH}$

Os seguintes sistemas-tampão foram usados: ácido cítrico/fosfato dissódico $(2,0-2,5)$; ácido cítrico/citrato de sódio $(3,0-3,5)$; ácido acético/acetato de sódio $(4,0-4,5)$; ácido cítrico/citrato de sódio $(5,0-5,5)$; monofosfato/fosfato dissódico $(6,0-7,0)$; Tris- $\mathrm{HCl}$ $(7,5-8,5)$ e ácido bórico/borato de sódio $(9,0-10,0)$, na concentração de $50 \mathrm{mM}$. As determinações das atividades de lipoxigenases nos respectivos valores de $\mathrm{pH}$ foram realizadas misturando-se $1,0 \mu \mathrm{L}$ do extrato bruto foliar e $4,0 \mu \mathrm{L}$ da solução-estoque de linoleato de sódio a 1,0 mL de tampão $0,05 \mathrm{M}$ de cada um dos respectivos $\mathrm{pH}$ descritos acima. A velocidade da reação, a $234 \mathrm{~nm}$, foi determinada de 30 em 30 segundos por um período de 120 segundos, a $25^{\circ} \mathrm{C}$. Baseando-se nas absorvâncias obtidas, calcularam-se as velocidades de formação de hidroperóxidos do ácido linoléico, como descrito anteriormente.

\section{Determinação da atividade de lipoxigenases em várias temperaturas}

O efeito da temperatura sobre a taxa de oxidação do ácido linoléico catalisada pela ação das lipoxigenases foi determinado a 20, 25, 30, 35, 40,45 e $50^{\circ} \mathrm{C}$. Foi utilizado banho-maria para que as soluções alcançassem as respectivas temperaturas, como também espectrofotômetro com controle de temperatura.

As misturas de reação foram realizadas utilizando-se $1,0 \mathrm{~mL}$ de tampão fosfato $50 \mathrm{mM} \mathrm{pH}$ $6,0,4,0 \mu \mathrm{L}$ linoleato de sódio $10 \mathrm{mM}$ como substrato e 1,0 $\mu \mathrm{L}$ de extrato foliar de soja. As absorvâncias das soluções a $234 \mathrm{~nm}$ foram utilizadas para as determinações da atividade de lipoxigenases.

\section{Determinação dos parâmetros cinéticos}

As determinações dos parâmetros cinéticos de lipoxigenases foram realizadas utilizando-se $1,0 \mu \mathrm{L}$ de extrato bruto foliar, contendo cerca de $1,0 \mathrm{mg}$ de proteína por $\mathrm{mL}$ de solução, $1 \mathrm{~mL}$ de tampão fosfato $50 \mathrm{mM} \mathrm{pH} \mathrm{6,0} \mathrm{e}$ linoleato de sódio como substrato, nas concentrações de $1,0 \times 10^{-5} ; 2,0 \times 10^{-5} ; 4,0 \times 10^{-5}$; $8,0 \times 10^{-5} ; 16,0 \times 10^{-5} ; 32,0 \times 10^{-5}, 64,0 \times 10^{-5} \mathrm{e}$ $128 \times 10^{-5} \mathrm{M}$.

Os parâmetros cinéticos, no estado estacionário, foram obtidos por meio da regressão não linear, utilizado-se o programa de computação Enzifitter (Leatherbarrow, 1987).

\section{Determinação de inibidores de proteases nos extratos foliares}

Foi realizada com base na inibição da atividade da tripsina, utilizando-se D,L-BApNA como substrato. Os resultados obtidos foram convertidos em mg de tripsina inibida por grama de proteína, de acordo com o método de Kakade et al. (1974).

\section{Determinação de hexanal e aldeídos totais}

A determinação de hexanal foi realizada por cromatografia gasosa, segundo o método de Utumi et al. (1998). A determinação de aldeídos totais foi realizada pelo método colorimétrico desenvolvido por Santos et al. (1993), utilizando 3metil-2-benzotiazolinona hidrazona (MBTH) como reagente de cor.

\section{RESULTADOS E DISCUSSÃO}

Efeito do pH e da temperatura na atividade de lipoxigenase

Pelos resultados, verificam-se dois picos de $\mathrm{pH}$ mais acentuados de atividade específica de lipoxigenases, 4,0 e 6,0; para os dois cultivares, FT-Cristalina RCH e FT-Cristalina (Figura 1). Como trabalhou-se com extrato foliar contendo lipoxigenases e não com formas purificadas, sugere-se, pelos resultados que o pool de 
lipoxigenases contém formas das isoenzimas com maiores valores de atividade a $\mathrm{pH} 4,0$ e formas com maiores valores de atividade a $\mathrm{pH}$ 6,0, respondendo à injúria causada pelo palito e pelo patógeno; contudo, a atividade apresentou-se maior em $\mathrm{pH}$ 6,0 nos tratamentos. Christopher et al.

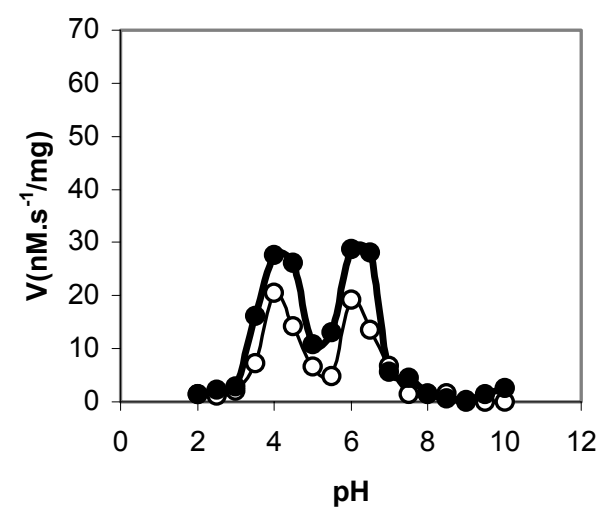

FT Cristalina RCH Infectada

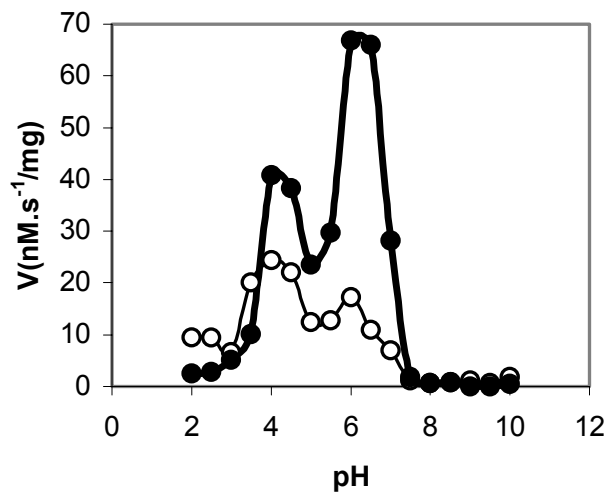

(1972), utilizando-se ácido linoléico como substrato de lipoxigenases de sementes de soja, demostraram que a LOX 1 tem atividade máxima em $\mathrm{pH}$ 9,5, a LOX 2, em pH 6,5, e a LOX 3 possui máxima atividade numa ampla faixa de $\mathrm{pH}$, ou seja, de pH 5,0 a 9,0.

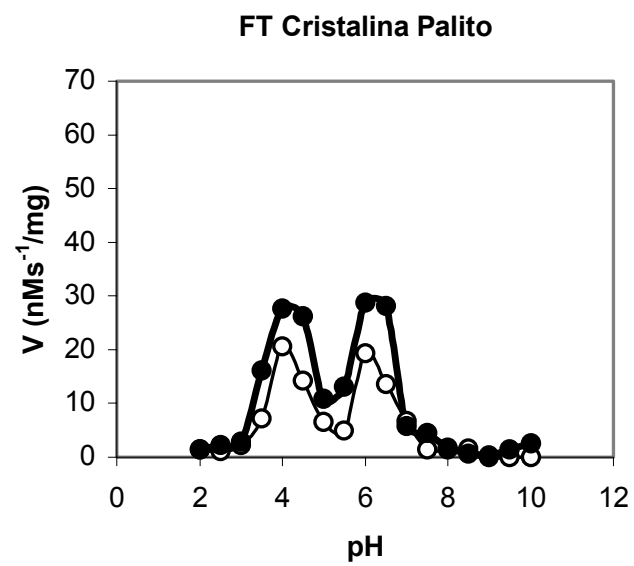

FT Cristalina RCH Palito

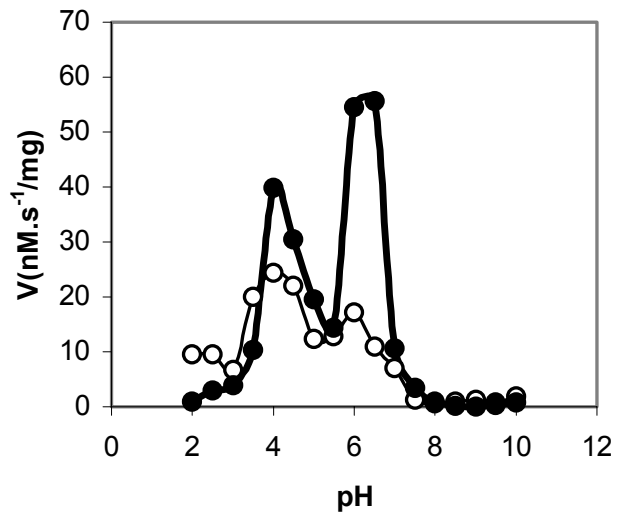

FIGURA 1 - Efeito do $\mathrm{pH}$ sobre a atividade específica, V(nM.s ${ }^{-1} / \mathrm{mg}$ de proteína), de lipoxigenases de folhas de soja nos cultivares FT Cristalina e FT Cristalina $\mathrm{RCH}$, infectadas pelo fungo Diaporthe phaseolorum (Cke. e Ell.) f. sp. meridionalis. Condições experimentais: enzima e substrato incubados a $25^{\circ} \mathrm{C}$, nos tampões a $0,05 \mathrm{M}$, concentração de ácido linoléico $4,0 \times 10^{-5} \mathrm{M}$, quantidade de extrato bruto, 1 $\mu \mathrm{L}$. Concentração de proteína solúvel para FT Cristalina infectada, FT Cristalina palito, FT Cristalina $\mathrm{RCH}$ infectada, FT Cristalina RCH palito, respectivamente: controles $-1,68 ; 1,79 ; 1,82 ; 1,80 \mathrm{mg} / \mathrm{ml}$, tratamentos $-1,75 ; 1,80 ; 1,79 ; 1,83 \mathrm{mg} / \mathrm{mL}$. 
O fato de haver mais de um pico de atividade pode estar relacionado ao fato de que, na planta, essas enzimas encontram-se organizadas em uma grande família multigênica que pode resultar, em dado tecido, na presença de um complexo de isoenzimas lipoxigenases que diferem quanto à especificidade pelo substrato, parâmetros físico-químicos e cinéticos.

Estima-se que o genoma de soja contém de 10 a 12 genes que expressam lipoxigenases (Koetje e Grimes, 1992). Além disso, tem sido relatado que o nível de atividade de lipoxigenases presentes em um dado tecido pode variar como resposta fisiológica da planta a diferentes tipos de estresses.

Kato et al. (1993) mostraram que a expressão do gene de soja para LOX-4 aumenta em folha após a remoção do dreno reprodutivo. Bunker et al. (1995) observaram a indução à expressão de dois genes adicionais de lipoxigenases lox A e $v l x \mathrm{C}$ em folhas de soja após a remoção da vagem. Saravitz e Siedow (1996) obtiveram aumento de LOX-7 e LOX-8 após a injúria mecânica em folhas de soja. Portanto, tem sido demostrado que a expressão de diferentes genes de lipoxigenases de soja tem sido induzida em folhas como resposta a diferentes estresses.

Os valores de atividade específica foram maiores nas plantas inoculadas com fungo e nas plantas injuriadas com o palito sem inóculo, que nos controles. De acordo com os resultados, podese inferir que ocorreu uma resposta da planta de soja ao ataque do patógeno e ao ferimento, mediante aumento da atividade de lipoxigenases.

Os dados apresentados estão dentro da faixa de $\mathrm{pH}$ ótimo descritas por outros autores: Minguez-Mosqueira et al. (1993), que relataram $\mathrm{pH}$ ótimo de lipoxigenases de pimentão em $\mathrm{pH}$ 5,0; Koch et al. (1992), que determinaram $\mathrm{pH}$ ótimo entre 6,4 e 7,2 em folhas de tomate inoculadas com Pseudomonas syringae e Lanna et al. (1996), que obtiveram valores de $\mathrm{pH}$ ótimo em 6,0 e 7,0 em folhas de soja.

O maior valor de atividade específica de lipoxigenases ocorreu a $25^{\circ} \mathrm{C}$ para ambos os cultivares (Figura 2). $\mathrm{O}$ pico a $25^{\circ} \mathrm{C}$ indica que não há diferença de estabilidade térmica dentro das isoformas de lipoxigenases foliares de soja analisadas. Adicionalmente, verifica-se mais uma vez que a atividade específica foi maior em plantas inoculadas pelo patógeno e nas plantas injuriadas pelo palito, sugerindo, novamente, que ocorreu uma resposta da planta de soja pelo aumento da atividade das lipoxigenases. Esse mesmo valor de temperatura ótima foi obtido por Lanna et al. (1996), quando analisaram o pool de lipoxigenases em folhas de soja dos genótipos IAC 100 "Triplo Nulo", IAC 100 e Cristalina, e por Vieira et al. (2001), analisando atividade de lipoxigenases foliares em plantas de soja submetidas a ferimento mecânico.

\section{Parâmetros cinéticos}

A determinação dos parâmetros cinéticos foi realizada a $\mathrm{pH} 6,0$, em tampão fosfato de sódio $50 \mathrm{mM}$ e a $25^{\circ} \mathrm{C}$. Esses valores de $\mathrm{pH}$ e temperatura foram os que apresentaram maiores valores de atividade em plantas inoculadas com o patógeno e injuriadas com o palito, ou seja, isoformas que apresentaram maiores respostas aos tratamentos. As lipoxigenases dos dois cultivares analisados apresentaram cinética de MichaelisMenten em todos os tempos analisados, na faixa de concentração de substrato utilizada (dados não mostrados). A tabela 1 apresenta os valores de $K_{M}$ app $\left(\mathrm{K}_{\mathrm{M}}\right.$ aparente) e $\mathrm{V}_{\text {máxapp }}$ (Vmáx aparente) para plantas submetidas à inoculação, à injúria e plantas sem injúria e inoculação (controle). Pode-se observar que nas plantas infectadas, tanto do cultivar FT-Cristalina como do cultivar FTCristalina $\mathrm{RCH}$, os valores de $\mathrm{K}_{\mathrm{M}}$ app foram decrescendo com o tempo (horas) de tratamento, ou seja, diminuíram tanto nas plantas tratadas com palito quanto nas inoculadas com o fungo.

$O$ valor numérico de $K_{M}$ estabelece um valor aproximado para o nível intracelular de substrato, ou seja, o $\mathrm{K}_{\mathrm{M}}$ reflete o ambiente celular, a concentração do substrato normalmente encontrado in vivo pela enzima e a química da reação que está sendo catalisada. $K_{M}$ é uma constante para uma dada enzima, isto é, seu valor 
numérico fornece um meio de comparação entre enzimas de diferentes organismos, ou de diferentes tecidos do mesmo organismo, ou do mesmo tecido em diferentes estágios de desenvolvimento. Entretanto, $V_{\max }$ não é uma constante cinética, ao passo que o $K_{M}$ é; assim, a $V_{\max }$ é um parâmetro cinético que depende da constante catalítica e da concentração da enzima pura no experimento. Assim, a constante de Michaelis indica a adequacidade relativa de substratos alternativos para uma determinada enzima, ou seja, o substrato com valor mais baixo de $\mathrm{K}_{\mathrm{M}}$ tem uma afinidade

FT Cristalina Infectada

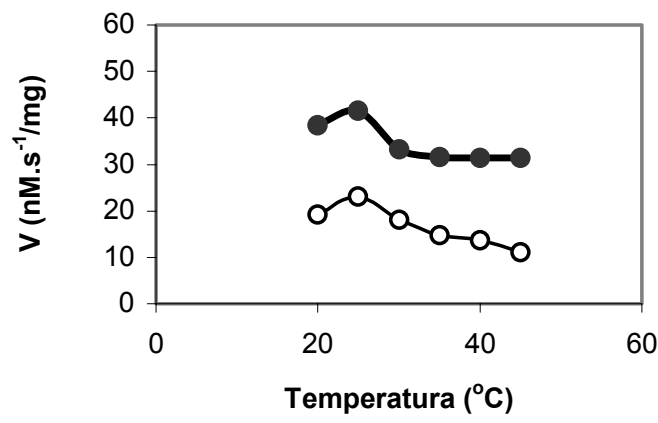

FT Cristalina RCH Infectada

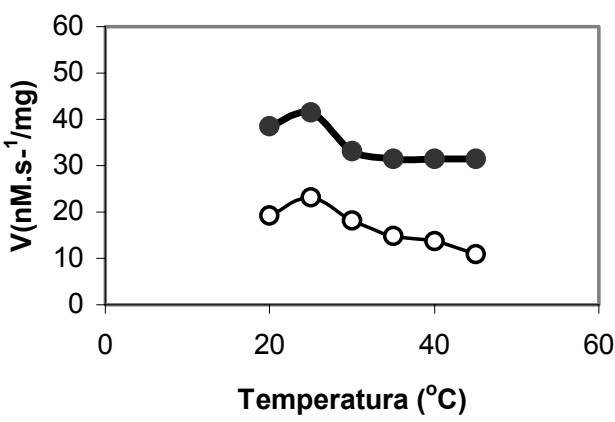

aparente maior para a enzima (Segel, 1975 e Lehninger et al., 1995). Portanto, o decréscimo nos valores de $K_{M}$ app em plantas infectadas e injuriadas com o palito sugerem uma melhor adaptação do substrato ao centro ativo da enzima e, portanto, uma melhoria na eficiência da catálise das lipoxigenases. Além disso, os diferentes valores de $K_{M}$ app sugerem, também, alteração na composição do pool de lipoxigenases de plantas de soja dos dois cultivares em resposta à injúria e à infecção pelo patógeno causador do cancro-da-haste.

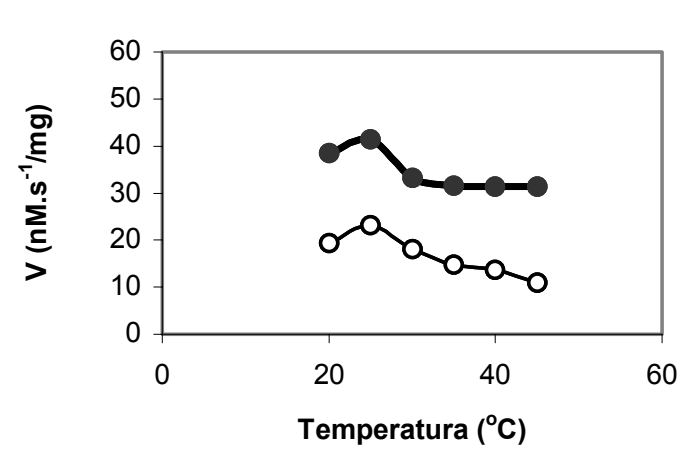

FIGURA 2 - Efeito da temperatura sobre a atividade específica, V(nM.s ${ }^{-1} / \mathrm{mg}$ de proteína), de lipoxigenases de folhas de soja nos cultivares FT Cristalina e FT Cristalina $\mathrm{RCH}$, infectadas pelo fungo Diaporthe phaseolorum (Cke. e Ell.) f. sp. meridionalis. Condições experimentais: enzima e substrato incubados a $25{ }^{0} \mathrm{C}$, nos tampões a $0,05 \mathrm{M}$, concentração de ácido linoléico $4,0 \times 10^{-5} \mathrm{M}$, quantidade de extrato bruto, $1 \mu \mathrm{L}$. Concentração de proteína solúvel para FT Cristalina infectada, FT Cristalina palito, FT Cristalina RCH infectada, FT Cristalina RCH palito, respectivamente: controles $-1,05 ; 1,10 ; 1,14 ; 1,12 \mathrm{mg} / \mathrm{ml}$, tratamentos $-1,11 ; 1,15 ; 1,13 ; 1,17 \mathrm{mg} / \mathrm{mL}$. 
Silva et al.

TABELA 1 - Parâmetros cinéticos de Lipoxigenases de folhas de soja dos cultivares FT Cristalina e FT Cristalina $\mathrm{RCH}$, injuriadas pelo palito e infectadas pelo fungo Diaporthe phaseolorum (Cke. e Ell.) f. sp. meridionalis. (a)

\begin{tabular}{|c|c|c|c|c|c|c|}
\hline \multirow{4}{*}{$\begin{array}{l}\text { Tempo } \\
\text { Após } \\
\text { Injúria } \\
\text { (horas) }\end{array}$} & \multicolumn{6}{|c|}{ Parâmetros Cinéticos - FT Cristalina } \\
\hline & \multicolumn{2}{|c|}{ Controle } & \multicolumn{2}{|c|}{ Palito } & \multicolumn{2}{|c|}{ Infectada } \\
\hline & $\mathrm{K}_{\text {mapp }}$ & $\mathrm{V}_{\text {máxapp }}$ & $\mathrm{K}_{\text {mapp }}$ & $\mathrm{V}_{\text {máxap }}$ & $\mathrm{K}_{\text {mapp }}$ & $\mathrm{V}_{\text {máxapp }}$ \\
\hline & $(\mu \mathrm{M})$ & $\left(\mathrm{nM} . \mathrm{s}^{-1}\right)$ & $(\mu \mathrm{M})$ & $\left(\mathrm{nM} . \mathrm{s}^{-1}\right)$ & $(\mu \mathrm{M})$ & $\left(\mathrm{nM} \cdot \mathrm{s}^{-1}\right)$ \\
\hline 0 & 260,05 & 145,84 & 280,43 & 151,54 & 258,15 & 155,29 \\
\hline 24 & 282,37 & 151,83 & 285,56 & 146,42 & 260,00 & 145,44 \\
\hline 48 & 278,56 & 168,92 & 263,00 & 120,12 & 163,37 & 52,34 \\
\hline \multirow[t]{2}{*}{96} & 262,23 & 120,05 & 251,17 & 118,21 & 158,52 & 51,55 \\
\hline & \multicolumn{6}{|c|}{ Parâmetros Cinéticos - FT Cristalina RCH } \\
\hline $\begin{array}{l}\text { Aempo } \\
\text { Após }\end{array}$ & \multicolumn{2}{|c|}{ Controle } & \multicolumn{2}{|c|}{ Palito } & \multicolumn{2}{|c|}{ Infectada } \\
\hline Injúria & $\mathrm{K}_{\text {mapp }}$ & $\mathrm{V}_{\text {máxapp }}$ & $\mathrm{K}_{\text {mapp }}$ & $\mathrm{V}_{\text {máxapp }}$ & $\mathrm{K}_{\text {mapp }}$ & $\mathrm{V}_{\text {máxapp }}$ \\
\hline (horas) & $(\mu \mathrm{M})$ & $\left(\mathrm{nM} \cdot \mathrm{s}^{-1}\right)$ & $(\mu \mathrm{M})$ & $\left(\mathrm{nM} . \mathrm{s}^{-1}\right)$ & $(\mu \mathrm{M})$ & $\left(\mathrm{nM} \cdot \mathrm{s}^{-1}\right)$ \\
\hline 0 & 378,78 & 214,95 & 355,40 & 177,93 & 320,47 & 177,90 \\
\hline 24 & 392,42 & 227,96 & 338,61 & 163,37 & 321,92 & 137,76 \\
\hline 48 & 380,67 & 170,20 & 203,22 & 80,55 & 198,63 & 73,03 \\
\hline 96 & 379,92 & 223,46 & 148,15 & 50,35 & 122,97 & 84,66 \\
\hline
\end{tabular}

a) Condições experimentais: reação em tampão fosfato de sódio $0,05 \mathrm{M}, \mathrm{pH} 6,0$ a $25{ }^{0} \mathrm{C}$. Concentração de ácido linoléico 0,01 a 1,28 mM. Quantidade de extrato bruto $1 \mu \mathrm{L}$ Concentração média de proteína solúvel nos 24 extratos bruto próximo a $1,0 \mathrm{mg} / \mathrm{mL}$.

Observa-se, ainda, uma melhoria na eficiência catalítica das lipoxigenases das plantas resistentes, FT-Cristalina $\mathrm{RCH}$, uma vez que que os valores de $\mathrm{K}_{\mathrm{M} \text { app }}$ foram ligeiramente menores do que na variedade FT-Cristalina, susceptíveis ao patógeno. Essa melhoria na eficiência catalítica poderá estar promovendo o aumento dos produtos da Via das Lipoxigenases, produtos esses inibidores de proteases e aldeídos que infere-se, são produzidos quando plantas são atacadas por fungos patogênicos (Vaughn e Gardner, 1993), insetos e protozoários (Croft et al., 1993).

\section{Determinação de inibidores de proteases}

Como um dos produtos da Via das Lipoxigenases é o ácido jasmônico, sendo esse um sinalizador para ativação de genes que codificam inibidores de proteases, realizou-se a determinação de inibidores de proteases, os quais foram expressos em miligrama de tripsina inibida por grama de proteína (Tabela 2). Ocorreram aumentos significativos de inibidores de proteases nas plantas infectadas com o patógeno, tanto no cultivar FT Cristalina quanto no cultivar FTCristalina RCH. Porém, em ambos os cultivares, as plantas responderam com níveis mais altos de inibidores quando ocorreu ferimento em vez de infecção, isto é, a resposta mais pronunciada das plantas de soja foi observada no tratamento utilizando-se palito sem inóculo. Possivelmente esse efeito seja indireto, uma vez que pela Via das Lipoxigenases ocorre formação de ácido jasmônico e esse está envolvido na ativação de genes que expressam inibidores de proteases (Gardner, 1991 e Farmer e Ryan, 1992). Sugere-se, portanto, que o aumento no nível de inibidores de proteases foi causado em virtude, principalmente, da injúria 
mecânica causada pelo palito. Vieira et al. (2001) obtiveram aumento dos níveis de inibidores de proteases em plantas de soja submetidas à injúria mecânica nas folhas.

Pautot et al. (1991), em estudos com expressão gênica de inibidores de proteases em tomate, citam que, contrariamente aos dados com ferimentos, a indução sistêmica de genes de inibidores de proteases é limitada durante a agressão por patógenos, porém constitui um dos componentes de resposta a esse tipo de ataque. Farmer e Ryan, (1992) também relatam aumento no nível de inibidores de proteases após submeter plantas de tomate à injúria mecânica.

\section{Determinação dos níveis de hexanal e aldeídos totais}

A Via das Lipoxigenases produz, como um dos principais produtos finais, aldeídos. Relatos têm mostrado que esses aldeídos causam efeito inibitório sobre o crescimento de patógenos. Assim, determinou-se a produção de hexanal e de aldeídos totais, cujos resultados estão apresentados na Tabela 3. Os níveis de hexanal foram expressos por meio da área sob pico obtido pela cromatografia gasosa, e os níveis de aldeídos totais, expressos em absorbância a $635 \mathrm{~nm}$.
Em ambos os cultivares, FT-Cristalina e FT Cristalina $\mathrm{RCH}$, não houve aumento significativo no conteúdo de hexanal em plantas tratadas a 5\% de probabilidade. Observa-se também queda nos níveis de hexanal ao longo do tempo para as plantas-controles FT Cristalina e FT Cristalina $\mathrm{RCH}$. Provavelmente, outros aldeídos, preferencialmente o hexanal, foram formados pela Via das Lipoxigenases. Segundo Croft et al. (1993), pela Via das Lipoxigenases ocorre produção de aldeídos de seis carbonos, como o trans-2-hexenal, componente característico do sabor e odor de frutos e folhas, além de outros compostos carbonílicos.

Com relação aos níveis de aldeídos totais, o cultivar FT-Cristalina apresentou diferença significativa, a 5\% de probabilidade, nos tempos de 48 e 96 horas após tratamento, tanto para as plantas injuriadas com palito como para as inoculadas com o patógeno. No cultivar FT Cristalina $\mathrm{RCH}$, não houve diferença significativa a $5 \%$ de probabilidade entre os níveis de aldeídos totais de plantas-controle e plantas infectadas em todos os tempos analisados. Por esses resultados, sugere-se que diferentes formas de lipoxigenases estão atuando em ambos os cultivares analisados, tanto na planta infectada quanto na planta injuriada, por meio da produção de aldeídos.

TABELA 2 - Inibição de tripsina por extratos de folhas de soja dos cultivares FT Cristalina e FT Cristalina $\mathrm{RCH}$, injuriadas pelo palito e infectadas pelo fungo Diaporthe phaseolorum (Cke. e Ell.) f. sp. meridionalis. Médias seguidas por uma mesma letra maiúscula em cada linha e minúscula em cada coluna não diferem entre si a $5 \%$ de probabilidade pelo teste Tukey.

\begin{tabular}{|c|c|c|c|c|c|c|}
\hline \multirow{3}{*}{$\begin{array}{l}\text { Tempo } \\
\text { Após } \\
\text { Injúria } \\
\text { (horas) }\end{array}$} & \multicolumn{6}{|c|}{ Inibição de Tripsina (mg de Tripsina Inibida/g de Proteína) } \\
\hline & \multicolumn{3}{|c|}{ FT Cristalina } & \multicolumn{3}{|c|}{ FT Cristalina RCH } \\
\hline & Controle & Palito & Infectada & Controle & Palito & Infectada \\
\hline 0 & $13,88 \mathrm{Db}$ & $102,65 \mathrm{Ac}$ & $27,35 \mathrm{Bb}$ & $13,64 \mathrm{CDa}$ & $22,79 \mathrm{Bc}$ & $16,65 \mathrm{Cb}$ \\
\hline 24 & $5,33 \mathrm{Dc}$ & $10,30 \mathrm{Cd}$ & $6,14 \mathrm{Dc}$ & $12,61 \mathrm{Ca}$ & $68,27 \mathrm{Ab}$ & $17,58 \mathrm{Bb}$ \\
\hline 48 & $17,54 \mathrm{Da}$ & $172,05 \mathrm{Aa}$ & $151,50 \mathrm{Ba}$ & $14,86 \mathrm{Da}$ & $173,67 \mathrm{Aa}$ & $48,50 \mathrm{Ca}$ \\
\hline 96 & $20,74 \mathrm{Ca}$ & $141,89 \mathrm{Ab}$ & $30,97 \mathrm{Bb}$ & $11,07 \mathrm{Ea}$ & $18,86 \mathrm{CDc}$ & $14,55 \mathrm{DEb}$ \\
\hline
\end{tabular}


TABELA 3 - Níveis de hexanal (área do pico) e aldeídos totais em folhas de soja dos cultivares FT Cristalina e FT Cristalina $\mathrm{RCH}$, injuriadas pelo palito e infectadas pelo fungo Diaporthe phaseolorum (Cke. e Ell.) f. sp. meridionalis. Médias seguidas por uma mesma letra maiúscula em cada linha e minúscula em cada coluna não diferem entre si ao nível de 5\% de probabilidade pelo teste Tukey.

\begin{tabular}{|c|c|c|c|c|c|c|}
\hline \multirow{3}{*}{$\begin{array}{l}\text { Tempo } \\
\text { após } \\
\text { Injúria } \\
\text { (Horas) }\end{array}$} & \multicolumn{6}{|c|}{ Níveis de Hexanal $\left(\mu \mathrm{V} \cdot \mathrm{Min}^{-1}\right)$} \\
\hline & \multicolumn{3}{|c|}{ FT Cristalina } & \multicolumn{3}{|c|}{ FT Cristalina RCH } \\
\hline & Controle & Palito & Infectada & Controle & Palito & Infectada \\
\hline 0 & $2412 \mathrm{Aa}$ & 2334 Aba & $1971 \mathrm{Bb}$ & $2807 \mathrm{Aa}$ & $2468 \mathrm{Aa}$ & $2575 \mathrm{Aa}$ \\
\hline 24 & $2026 \mathrm{Ab}$ & $1407 \mathrm{Dbc}$ & $2575 \mathrm{Aa}$ & $2575 \mathrm{Aa}$ & $2095 \mathrm{Bab}$ & $1919 \mathrm{Bb}$ \\
\hline 48 & $1477 \mathrm{BCc}$ & $1183 \mathrm{Ec}$ & $1919 \mathrm{Bb}$ & $1919 \mathrm{Bb}$ & $1555 \mathrm{Bc}$ & $1212 \mathrm{Dec}$ \\
\hline 96 & $1542 \mathrm{Cc}$ & $1688 \mathrm{BCb}$ & $1212 \mathrm{Dec}$ & $1212 \mathrm{Dec}$ & $1707 \mathrm{BCbc}$ & $1603 \mathrm{Cbc}$ \\
\hline \multirow{3}{*}{$\begin{array}{l}\text { Tempo } \\
\text { após } \\
\text { Injúria } \\
\text { (horas) }\end{array}$} & \multicolumn{6}{|c|}{ Níveis de Aldeídos Totais $\left(\mathrm{A}_{635}\right)$} \\
\hline & \multicolumn{3}{|c|}{ FT Cristalina } & \multicolumn{3}{|c|}{ FT Cristalina RCH } \\
\hline & Controle & Palito & Infectada & Controle & Palito & Infectada \\
\hline 0 & $0,9687 \mathrm{ABCa}$ & $0,9289 \mathrm{Ca}$ & $0,9395 \mathrm{BCc}$ & $1,0220 \mathrm{Aa}$ & $1,0112 \mathrm{Aba}$ & $1,0218 \mathrm{Aa}$ \\
\hline 24 & $0,9579 \mathrm{Bca}$ & $0,9332 \mathrm{Ca}$ & $0,9638 \mathrm{BCbc}$ & $1,0117 \mathrm{Aba}$ & $1,0196 \mathrm{Aa}$ & $0,9769 \mathrm{ABCa}$ \\
\hline 48 & $0,9223 \mathrm{BCb}$ & $0,8791 \mathrm{Cb}$ & $0,9798 \mathrm{Ab}$ & $0,9784 \mathrm{Aba}$ & $1,0212 \mathrm{Aa}$ & $1,0005 \mathrm{Aa}$ \\
\hline 96 & $0,8670 \mathrm{Cc}$ & $0,9519 \mathrm{Ba}$ & $1,0208 \mathrm{Aa}$ & $0,9795 \mathrm{ABa}$ & $0,9948 \mathrm{ABa}$ & $1,0117 \mathrm{Aa}$ \\
\hline
\end{tabular}

Pelos resultados dos parâmetros bioquímico e cinéticos de lipoxigenases, assim como pelos produtos da via, verifica-se que ocorreu resposta das plantas das variedades FT Cristalina e FT Cristalina $\mathrm{RCH}$, tanto nas plantas inoculadas com o patógeno quanto nas submetidas à injúria com palito sem o inóculo. Possivelmente o mecanismo de resistência ao patógeno não esteja envolvido diretamente com a Via das Lipoxigenases, uma vez que o efeito da injúria foi bastante marcante. Entretanto, os parâmetros bioquímicos e cinéticos sugerem uma resposta das plantas de soja através das Via das Lipoxigenases

\section{AGRADECIMENTOS}

Os autores agradecem à FAPEMIG pelo apoio financeiro.

\section{REFERENNCIAS}

ANDERSON, J.M.; SILATRO, S.R.; KLAUER, S.F.; FRANCESCHI, V.R. Jasmonic aciddependent increases in the level of vegetative storage proteins in soybean. Plant Science, 62:45-52, 1989.

AXELROD, B.; CHEESBROUGH, T.M.; LAASKO, S. Lipoxygenases from soybeans. Methods Enzymol, 71:441-451, 1981.

BELL, E.; MULLET, J.E. Caracterization of an arabidopsis lipoxygenase gene responsive to methyl jasmonate and wounding. Plant Physiol, 103:1133-1137, 1993.

BOHLAND, C.; BALKENHOHL, T.; LOERS G.; FEUSSNER I.; GRAMBOW, H.J. Differential induction of lipoxygenases isoforms in wheat upon treatment with rust fungus elicitor, chitin oligossaccharides, chitosan, and methyl jasmonate. Plant Physiol, 114:679-685, 1997. 
BUNKER, T.W.; KOETJE, D.S.; STEPHENSON, L.C.; CREELMAN, R.A.; MULLET, J.E.; GRIMES, H.D. Sink limitation induces the expression of multiple soybean lipoxygenase mRNAs while the endogenous jasmonic acid level remains low. Plant Cell, 7:1319-1331, 1995.

CHRISTOPHER, J.P.; PISTORIOUS, E.K.; AXELROD, B. Isolation of a third isoenzyme of soybean lipoxygenase. Biochem Biophys Acta, v.284, p.54-62, 1972.

CROFT, K.P.C.; JÜNTTER, F.; SLUSARENKO, A.J. Volatiles products of the lipoxygenase pathway envolved from Phaseolus vulgaris (L) leaves inoculated with Pseudomonas syringae pv phaseolicola. Plant Physiol, 101:13-24, 1993.

EMBRAPA. Centro Nacional de Pesquisa de Soja (Londrina, PR). Recomendações Técnicas para a Cultura da Soja na Região Central do Brasil 2000/01. Londrina, 2000. 245p.

FARMER, E.E.; RYAN, C.A. Octadecanoid precursors of jasmonic acid activate the syntesis of wounding inducible proteinase inhibitors. Plant Cell, 4:129-134, 1992.

FEHR, W.R.; CAVINESS, C.E.; BURMOOD, D.T.; PENNINGTOON, J.S. Stages development descriptions for soybeans, Glycine $\max$ (L.) Merrill. Crop Science, 11:91-93, 1971

FIDANTSEF, A.L.; BOSTOCK, R.M. Characterization of potato tuber lipoxygenase cDNAs and lipoxygenase expression in potato tubers and leaves. Physiologia Plantarum, 102:257-271, 1998.

GARDNER, H.W. Recent investigation into the lipoxygenase pathway of plants. Biochem Phys Acta, 1084:221-239, 1991.

HEITZ, T.; BERGEY, D.R.; RYAN, C.A. A gene encoding a chloroplast-targeted lipoxygenase in tomato leaves is transiently induced by wounding, systemin, and methyl jamonate. Plant Physiol, 114:1085-1093, 1997.

HILDEBRAND, D.F. Lipoxygenases. Physiologia Plantarum, 76:249-253, 1989.
KAKADE, M.L.; RACKIS, J.J.; McGHEE, J.E.; PUSKI, G. Determination of trypsin inhibitor activity of soy products: a collaborative analysis of an improved procedure. Cereal Chemistry, 51:376-382, 1974.

KATO, T.; SHIRANO, Y.; IWAMOTO, H.; SHIBATA, D. Soybean lipoxigenase L-4, a component of the 94-kilodalton storage protein in vegetative tissue: expression and accumulation in leaves induced by pod removal and by methyl jasmonate. Plant Cell Physiol, 34:1063-1072, 1993.

KOCH, E.; MEIER, B.M.; EIBEN, H.G.; SLUSARENKO, A. A lipoxygenase from leaves of tomato (Lycopersicon esculentumm Mill) is induced in response to plant pathogenic Pseudomonas. Plant Physiol, 9:571-576, 1992.

KOETJE, D.S.; GRIMES, H.D. Molecular characterization of $\operatorname{lox} \mathrm{N}$, a nitrogen-responsive lipoxygenase gene of soybeans. Plant Physiol, abstract 484, 99:S-81, 1992.

LANNA, A.C.; OLIVEIRA, M.G.A.; BARROS, E.G.; MOREIRA, M.A. Kinetic parameters of leaf lipoxygenase pools from normal soybean genotypes and a line devoid of seed lipoxygenases. Brazilian Journal of Plant Physiology, 8:87-92, 1996.

LEATHERBARROW, R.J. Enziffiter manual. London: Biosoft., p.13-42, 1987.

LEHNINGER, A.L.; NELSON, D.L.; COX, M.M. Princípios de bioquímica. São Paulo, Editora Sarvier, 1995. 839p.

MACK, A.J.; PETERMAN, T.K.; SIEDOW, J.N. Lipoxygenase isoenzymes in higher plants: biochemical properties and physiological role. Current Topics Biolog Medi Resear, 13:12754, 1987.

MELAN, M.A.; DONG, X.; ENDARA, M.E.; DAVIS, K.R.; AUSUBEL, F.M.; PETTERMAN, T.K. An Arabidopsis thaliana lipoxygenase gene can be induced by pathogens, abscisic acid, and methyl jasmonate. Plant Physiol, 101:441-450, 1993. 
MINGUEZ-MOSQUEIRA, M.I.; JARENGALAN, M.; GARRIDO-FERNANDEZ，J. Lipoxygenase activity during pepper ripening and processing of paprika. Phytochemistry, 32:1103-1108, 1993.

OHTA, H.; IDA, S.; MIKAMI, B.; MORITA, Y. Changes in lipoxygenase components of rice seedling during germination. Plant Cell Physiol., 22:911-918, 1986.

PARÉ, P.W.; TUMLINSON, J.H. De novo biosyntesis of volatiles inducible by insect herbivory in cotton plants. Plant Physiol, 114:1161-1167, 1997.

PARK, T.K.; HOLLAND, M.A.; LASKEY, J.G.; POLACCO, J.C. Germination- associated lipoxygenases transcripts persist in maturing soybean plants and are induced by jasmonate. Plant Science, 96:109-117, 1994.

PAUTOT, V.; HOLZER, F.M.; WALLING, L.L. Differential expression of tomato proteinase inhibitor I and II genes during bacterial pathogen invasion and wounding. Molecular Plant-Microbe Interations, 4:284-292, 1991.

ROUET-MAYER, M.; BUREAU, J.; LAURIERI, C. Identification and characterization of lipoxygenase isoforms in senescing carnation petals. Plant Physiol, 98:971-978, 1992.

SANTOS, I.C.; REIS, W.J.P.; MOREIRA, M.A.; REZENDE, S.T.; ROCHA, V.S.; SEDIYAMA, C.S. Determinação de aldeídos totais para avaliar o potencial de germinação de sementes de soja. Revista Ceres, 40:438444, 1993.

SARAVITZ, D.M.; SIEDOW, J.N. The differential expression of wound-inducible lipoxygenase genes in soybean leaves. Plant Physiol, 110:287-299, 1996.

SEGEL, I.H. Enzyme kinetics. John Wiley e Sons, New York, 1975. 957p.

SIEDOW, J.N. Plant lipoxygenase: struture and function. Ann. Rev. Plant Physiol Plant Mol Biol, 42:145-188, 1991.

SILVA, M.D. Avaliação bioquímica da Via das Lipoxigenases em plantas de soja infectadas com cancro da haste. Viçosa: Universidade
Federal de Viçosa, 1999. 43p. Tese de Mestrado.

SMITH, P.K.; KROHN, R.I.; HERMANSON, G.T.; MALLIA, A.K.; GARTNER, F.H.; PROVENZANO, M.D.; FUJIMOTO, E.K.; GOEKE, N.M.; OLSON, B.J.; KLENK, D.C. Measurement of protein using bicinchoninic acid. Anal Biochem, 15:76-85, 1985.

STEPHENSON, L.C.; BUNKER, T.W.; DUBBS, W.E.; GRIMES, H.D. Specifc soybean lipoxygenases localize to discrete subcellular compartments and their mRNAs are differentially regulated by source-sink status. Plant Physiol, 116:923-933, 1998.

TRANBARGER, T.J.; FRANCESCHI, V.R.; HILDEBRAND, D.F.; GRIMES, H.D. The soybean 94-kilodalton vegetative storage protein is a lipoxygenase that is localized in paraveinal mesophyll cell vacuoles. Plant Cell, 3:973-987, 1991.

UTUMI, M.M.; BARROS, E.G.; OLIVEIRA, M.G.A.; SEDIYAMOA, C.S.; MOREIRA, M.A. Efeito da eliminação genética de lipoxigenases e de polipeptídeos de reserva na qualidade da proteína da soja. Revista Brasileira de Fisiologia Vegetal, 10:203-212, 1998.

VAUGHN, S.F.; GARDNER, H.W. Lipoxygenase-derived aldehides inhibit fungi pathogenic on soybean. J. Chem. Ecol, 19:2337-2345, 1993.

VICK, B.; ZIMMERMAN, D.C. Oxidative systems for modification of fatty acids: the lipoxygenase pathway. In: STUMPF, P.K., CONN, E.E. (Eds.) The Biochemistry of Plants. Orlando: Academic Press, 9:53-97, 1987.

VIEIRA, A.A. Biochemical evaluation of lipoxygenase pathaway of soybean plants submitted to.wounding. Brazilian Journal of Plant Physiology, 13:5-12, 2001.

YORINORI, J.T. Metodologia de produção de Diaphorte phaseolorum f. sp. meridionalis. Fitopatologia Brasileira, 20: 276-277, 1995. Suplemento. 
